\title{
Konsep Aqal Dalam Alquran dan Relevansinya dengan Pendidikan Islam
}

(The Concept of Aqal in the Qur'an and its Relevance to Islamic Education)

\author{
Shelly Alvareza Zazkia \\ Universitas Islam Negeri (UIN) Sunan Kalijaga Yogyakarta \\ shellyalvarezazazkia@gmail.com
}

DOI: $10.29240 /$ alquds.v5i1.2342

Submitted: 2021-01-17| Revised: 2021-06-04 | Accepted: 2021-06-28

\begin{abstract}
Intellect is the greatest gift to humans as the best creation and as a differentiator from other creatures. The phenomenon in this era is that many people misuse their intellect and intelligence for bad things such as lying, stealing, corruption, and following mere lust. This paper aims to restore the concept and function of reason in accordance with the guidance of the Qur'an and its relevance to the world of Islamic education. This research is a library research. The analysis obtained is that reason makes people think, reflect, distinguish between haq and vanity, right and wrong, and receive all kinds of information, all of which can be used in Islamic education as a mutual scientific benefit so as to create a better Islamic life order.
\end{abstract}

Keywords: Intellect, Al-Qur'an, Islamic Education

\begin{abstract}
Abstrak. Akal merupakan anugerah terbesar bagi manusia sebagai ciptaan terbaik dan sebagai pembeda dengan makhluk yang lain. Fenomena di zaman ini banyak manusia menyalahgunakan akal dan kepintarannya untuk hal-hal yang buruk seperti berbohong, mencuri, korupsi, dan mengikuti hawa nafsu belaka. Tulisan ini bertujuan untuk menemukan konsep aqal dalam Al-quran dan bagaimana relevansinya dengan Pendidikan Islam menggunakan metode Tafsir Maudhui. Penelitian ini merupakan penelitian kepustakaan. Analisis yang diperoleh adalah akal menjadikan manusia dapat berpikir, merenung, membedakan antara haq dan batil, benar dan salah, dan menerima segala jenis informasi pengetahuan, yang itu semua dapat dipergunakan dalam pendidikan Islam sebagai kemaslahatan keilmuan bersama sehingga terciptanya tatanan kehidupan Islami yang lebih baik.
\end{abstract}

Kata kunci: Akal, Al-Qur'an, Pendidikan Islam

\section{Pendahuluan}

Manusia sebagai Khalifah fil Ardh diberikan oleh Allah SWT segala perangkat dalam menjalankan tugasnya yaitu memakmurkan bumi di antaranya 
adalah akal. Tulisan ini setidaknya membahas dua inti utama dari tujuan analisis penelitian, yaitu, tentang konsep akal dalam Al-Quran dan relevansinya dengan dunia pendidikan.

Dalam Surat At-Tin ayat 4 Allah menegaskan bahwa manusia dengan segala perangkatnya diciptakan sebagai makhluk dalam bentuk terbaik. Manusia juga merupakan makhluk yang kompleks (memiliki taqwa dan nafsu). Sebab itu Allah memberikan akal untuk manusia guna sebagai penimbang dan penyeimbang. Sehingga dengan akal manusia dalam hidupnya mampu menimbang antara yang haq dan bathil, antara benar dan salah, antara taqwa dan nafsu, dan mampu menyeimbangkan keduanya. ${ }^{1}$ Salah satu tujuan akal diberikan kepada manusia agar manusia berbeda dengan hewan dan makhluk lainnya. Karena akal manusia menjadi mulia, menjadi makhluk terbaik, diangkat derajatnya, terlebih dengan ilmu pengetahuan. Seandainya manusia kehilangan akal atau akal dicabut darinya maka manusia akan seperti hewan. ${ }^{2}$

Meski demikian banyak orang yang salah menggunakan akal dan kepintarannya. Ada orang pandai berbohong, ia menjadi koruptor. Ada orang pandai merencanakan sesuatu, ia menjadi pencuri. Sehingga banyak dari manusia yang menyalahgunakan pemberian dari Allah tersebut. Tidak sedikit juga dari mereka menggunakan akalnya hanya untuk menuruti hawa nafsu dunia, seperti harta, tahta, dan wanita. Manusia seperti itu disebutkan oleh Al-Quran lebih rendah daripada binatang. ${ }^{3}$ Oleh karena itu tulisan ini bertujuan untuk menemukan konsep aqal dalam Alquran dan bagaimana relevansinya dengan Pendidikan Islam.

Penulis telah mereview penelitian-penelitian terdahulu yang dapat dijadikan landasan dan memiliki korelasi dengan penelitian ini, yaitu peneltian yang dilakukan oleh Khudiatul Chairuni tentang pengaruhnya belajar ilmu agama Islam dengan kecerdasan dan religiuisitas siswa. Chariuni melakukan penelitian pada siswa SMP Bakti Mulya 400 Jakarta, dengan data 34\%, sedangkan sisanya dipengaruhi oleh faktor lain. ${ }^{4}$ Penelitian Chariuni sejalan dengan penelitian ini,

Hlm. 22

${ }^{1}$ Haldar Musyafa, Dahsyatnya Potensi Akal Dan Hati Kita (Yogyakarta: Suka Press, 2015).

${ }^{2}$ Cyril Glasse, Ensiklopedi Islam Ringkas Terjemah Ghufron Masadi (Jakarta: RajaGrafindo Persada, 1996), hlm. 34.

${ }^{3}$ Lihat: Surat Al-Furqon ayat 44.

${ }^{4}$ Khudiatul Chairuni, "Pengaruh Belajar PAI Terhadap Religiusitas Peserta Didik Di SMP Bakti Mulya 400 Jakarta", Skripsi, Pendidikan Agama Islam Fakultas Ilmu Tarbiyah Dan Keguruan Universitas Islam Negeri Syarif Hidayatullah Jakarta 2019, hlm. 61. 
adapun dalam penelitian peneliti dengan lebih memfokuskan kepada pendayagunaan akal salah satunya untuk menerima segala informasi yang baik dengan itu sangat relevan terhadap pendidikan agama seseorang.

Tulisan ini menggunakan metode Tafsir Maudhui. Tafsir maudhui tersusun dari dua kata, yaitu tafsir dan maudhui. Tafsir mengandung arti sebagai penjelasan atau keterangan, adapun menurut istilah kata al-tafsir adalah ilmu yang menyingkap tentang makna-makna dari ayat-ayat Alquran yang dimaksud Allah SWT sesuai dengan kemampuan manusia. ${ }^{5}$ Sedangkan maudhui dapat diartikan dengan sesuatu yang ditaruh atau diletakkan. Karena maudhui sendiri merupakan bentuk isim maful dari fi'il madhi "wadho'a” yang berarti menaruh. Tafsir maudhui adalah lafadz dari bahasa Arab yang kalau diterjemahkan dalam bahasa Indonesia adalah tafsir tematik. ${ }^{6}$

Secara terminologi, setidaknya tafsir maudhui mempunyai dua bentuk yang berbeda. Pertama, pembahasan di dalam tafsir maudhui ialah membahas satu surat tertentu secara menyeluruh dan utuh dengan menjelaskan maksudnya dan juga menjelaskan korelasinya antar berbagai masalah yang ada di dalamnya. Sehingga isi dalam satu surat tersebut dapat terlihat dengan jelas. Kedua, menghimpun sejumlah ayat dari berbagai surat yang sama-sama membicarakan atau terkait dalam suatu masalah. Bentuk tafsir maudhui yang kedua ini yang paling popular di kalangan masyarakat. ${ }^{7}$ Metode tafsir maudhu'i juga disebut dengan metode tematik karena pembahasannya berdasarkan tema-tema tertentu yang terdapat dalam Al-Quran. ${ }^{8}$

\section{Pembahasan}

\section{Pengertian Al-‘aq1} hlm. 15

${ }^{5}$ Mustofa Muslim, Mahabahits fi Tafsir Maudhu'i, (Beirut: Darul Qolam, 1989),

${ }^{6}$ M. Sja'roni, "STUDI TAFSIR TEMATIK" dalam Jurnal study Islam Panca Wahana Vol.1, No.12, 2014, hlm. 2.

${ }^{7}$ Abd. Al-Hayy Al-Farmawi. Metode Tafsir Maudhu'iy. Cet.1 (Jakarta: PT Raja Grafindo Persada, 1994), hlm: 35-36. 2010), hlm. 47

${ }^{8}$ M. Alfatih Suryadilaga, dkk, Metodologi Ilmu Tafsir, Cet. III (Yogyakarta: Teras, 
Kata Al-'aql dari bahasa Arab yang secara bahasa memiliki arti akal atau fikiran. ${ }^{9}$ Kemudian diserap ke dalam bahasa Indonesia menjadi daya atau alat berpikir. ${ }^{10}$ Akal juga dapat digunakan untuk memahami, menemukan jalan, atau cara melakukan sesuatu. ${ }^{11}$ Selain menggunakan `aqala (akal), Al-Qur`an juga sering memakai ungkapan atau istilah yang menunjukkan arti berfikir, yaitu "nazhara" (memperhatikan), "tafakkara" (memikirkan), "faqqaha” (memahami), "tadabbara" (mentadaburi) dan "tazdakkara" (mengingat). ${ }^{12}$

Akal dalam perspektif pendidikan Islam. Selain menjadi penyeimbang antara taqwa dan nafsu, manusia diberikan akal tidak lain juga ditujukan agar mampu menerima segala informasi pengetahuan. Islam sangat memperhatikan dan mempedulikan urgensi pendidikan bagi umatnya. Karena pendidikan telah menempatkan kedudukannya sebagai pemegang peranan paling penting dalam diri setiap individu. Berkat pendidikan dan ilmu pengetahuan, manusia dapat menjalani aktivitas kehidupannya dengan baik, serta dapat menghadapi segala bentuk persoalan kehidupannya yang semakin kompleks. ${ }^{13}$

Akal dan ilmu pengetahuan dalam perspektif pendidikan Islam merupakan dua hal terkait dan tak terpisahkan. Pertumbuhan pemikiran agama seseorang bertepatan dengan pertumbuhan kecerdasan yang dimiliki. Perkembangan kemampuan kognitif memungkinkan seseorang untuk meninggalkan keyakinan serta pengetahuan agama sebelumnya yang diperoleh dari tempat tinggal, kemudian melahirkan konsep, dan berproses kepada keyakinan pribadi sejati pada agama. ${ }^{14}$ Menurut hasil penelitian Khudiatul Chairuni tentang pendidikan dan pembelajaran Islam aktif telah mempengaruhi keyakinan beragama siswa SMP Bakti Mulya 400 Jakarta, dengan data 34\%, Hlm. 957.

${ }_{9}^{9}$ Munawwir, Kamus Al-Munawwir Arab-Indonesia (Surabaya: Pustaka progressif, 1997).

${ }^{10}$ Poerwadarminta, Kamus Umum Bahasa Indonesia (Jakarta: Balai Pustaka, 2007). Hlm. 16.

${ }^{11}$ Tim Redaksi, Kamus Besar Bahasa Indonesia Edisi III (Jakarta: Balai Pustaka, 2005). Hlm. 18.

${ }^{12}$ Tim Penyusun, Ensiklopedi Islam, Jild. 1 (Jakarta: Ichtiar Baru Van Hoeve, 2005), hlm. 127.

13 Abd Hamid Wahid, Chusnul Muali dan Arofah Aprilia Putri, "Rekonstruksi Pendidikan Islam Kontemporer Dalam Perspektif Transformasi Sosial", jurnal Pendidikan Islam, Vol.07, No. 01, 2018, hlm. 1

${ }^{14}$ Sururin, Imu Jiwa Agama, (Jakarta: PT. Raja Grafindo Persada, 2004), Cet. ke-1, hlm. 67. 
sedangkan sisanya dipengaruhi oleh faktor lain. ${ }^{15}$ Penelitian ini menunjukkan bahwa kecerdasan (akal) sangat relevan dengan pendidikan agama untuk meningkatkan keberagamaan seseorang.

Berawal dari risalah mulia menuju peradaban dunia. Sejak wahyu diutus kepada Rasulullah SAW hingga Islam sampai berada di puncak kejayaan, salah satu faktor utamanya adalah pendidikan. Mulai dari Baghdad hingga Andalusia. ${ }^{16}$ Selain pendidikan juga disebabkan oleh kemajuan ekonomi dan sebagainya. Namun dengan era semakin modern berdampak kepada manusia yang umumnya ingin instan, tidak menggunakan akalnya untuk berpikir kritis. Oleh karena itu sebagai masyarakat madani sudah seharusnya manusia modern untuk mengulang kembali kejayaan atau kecemerlangan dalam peradaban Islam yang telah tercatat dengan tinta emas kemuliaan mereka, salah satunya dengan kemajuan pendidikan atau ilmu pengetahuan. ${ }^{17}$

Penulis mengutip perkataan Bernard Shaw yang berkata, "Sungguh agama yang dibawa oleh Muhammad merupakan tolak ukur yang tinggi dan mengagumkan. Andai saja orang seperti ia dijadikan pemimpin hari ini, maka ia akan mampu memecahkan segala problematika." 18 Beliau melanjutkan, "Jika ingin mengetahui bagaimana konsep pendidikan Nabi SAW kepada para sahabat, maka hendaklah ia kembali kepada sejarah agar dapat melihat jejak-jejak agung dan kemuliaan mereka". ${ }^{19}$

Oleh karena itu setidaknya ada dua istilah yang seharusnya berperan baik dalam pendidikan Islam, yaitu tafakeur dan tadzakkur. Tafakkur adalah kemampuan seorang hamba dalam menggunakan akalnya untuk berfikir sampai melahirkan rasa takut kepada Allah, kemudian mahabbah (rasa cinta) dan ma'rifah. Sedangkan Tadzakkur adalah tahap ketika seorang hamba sudah melewati proses bertafakkur yang membuatnya selalu mengingat Allah dimana pun mereka berada. Kedua hal ini menunjukkan betapa pentingnya dengan

${ }^{15}$ Khudiatul Chairuni, "Pengaruh Belajar PAI Terhadap Religiusitas Peserta Didik Di SMP Bakti Mulya 400 Jakarta", Skripsi, Pendidikan Agama Islam Fakultas Ilmu Tarbiyah Dan Keguruan Universitas Islam Negeri Syarif Hidayatullah Jakarta 2019, hlm. 61.

${ }^{16}$ Achmad Farid, Jejak Sejarah Andalusia, cet.1. (Yogyakarta: Checklist, 2018) hlm. Xiv.

${ }^{17}$ Wasehudin, 'Akal Dalam Perspektif Pendidikan Islam', Jurnal Al Qalam, Vol. 35, No. 2 (2018), Hlm. 14.

${ }_{18}$ Abdullah Nashih 'Ulwan, penerj. Arif Rahman Hakim dan Abdul Halim. Pendidikan Anak dalam Islam. (Solo: Insan Kamil, 2012) hlm. Xii.

${ }^{19} \mathrm{Ibid}, \mathrm{hlm}$. xiii. 
memiliki konsep Tafakkur dan Tafdzakkur yang baik menjadikan para pembelajar meniatkan setiap proses belajarnya hanya untuk Allah SWT, dengan begitu ilmu pengetahuan yang mereka pelajari dapat tertanam dalam jiwa dan diaplikasikan dalam kehidupan sehari-hari. ${ }^{20}$

\section{Ayat-Ayat Al-Qur'an Terkait Akal Dalam Perspektif Pendidikan Islam}

Akal yang dimiliki oleh setiap manusia umumnya digunakan berbedabeda dan tiada batas. Oleh karenanya Al-Quran membatasi serta memberikan tuntunan melalui ayat-ayat di dalamnya bagaimana seseorang menggunakan akalnya sesuai dengan fungsi yang telah Allah tetapkan. Di antaranya seperti berikut:

a. Surat Al-'Alaq ayat 1 (Membaca). Akal untuk menerima segala informasi pengetahuan.

Allah berfirman, "Bacalah dengan menyebut nama Tuhanmu yang menciptakan.” (Q.S. Al-“Alaq: 1)

Para ulama sepakat bahwa ayat 1 sampai 5 dalam Surat Al-'Alaq adalah wahyu pertama yang diturunkan kepada Nabi Muhammad SAW. Amati, pada saat itu kondisi masyarakat Arab sangat jahiliyah, kemusyrikan dan kekafiran merajalela di mana-mana. Lalu mengapa wahyu pertama yang turun adalah perintah untuk membaca, bukan seperti misalnya, "Hancurkanlah patungpatung", atau "Bebaskan keluargamu dari kemusyrikan", atau dengan bentuk contoh lainnya. Ternyata itu semua tidak dapat dilakukan tanpa memiliki ilmu pengetahuan yang cukup (membaca). Seseorang yang ingin berdakwah agar masyarakatnya kembali kepada jalan Allah SWT maka harus memiliki ilmu yang tinggi. ${ }^{21}$ Melihat begitu pentingnya membaca, maka sudah seharusnya setiap manusia menggunakan akalnya untuk mendapatkan segala pengetahuan dengan cara membaca.

b. Surat Al-Mujadalah ayat 11. (Akal untuk meningkatkan iman dan ilmu)

Allah SWT berfirman, “.........Allah akan meninggikan derajat semua orang beriman di antaramu dan semua orang yang diberi ilmu pengetahuan. Dan Allah Maha Mengetahui apa yang kamu kerjakan”. (Q.S. al-Mujadalah: 11).

20 Muhammad Mahfudz, Peran Akal Dalam Surat Ali Imran Ayat 190-191 Dan Implikasinya Dalam Pendidikan Islam (Semarang: Fakultas Tarbiyah IAIN Walisongo, 2006). Hlm. 210.

${ }^{21}$ Muh. Anis. Tafsir Ayat-Ayat Pendidikan dalam Al-Quran. (Yogyakarta: Mentari Pustaka, 2012), hlm. 78. 
Asbabun nuzul ayat ini adalah suatu ketika para sahabat sedang mempelajari suatu ilmu bersama Rasulullah SAW di majelis beliau, namun ada seorang sahabat lain yang datang terlambat lalu para sahabat yang lebih dulu bersama Rasulullah enggan memberikan tempat duduk untuk sahabat yang terlambat tersebut, maka turun ayat ini ${ }^{22}$ Setelah manusia menggunakan akalnya untuk mendapatkan pengetahuan, maka Allah berjanji akan meninggikan derajat mereka daripada orang-orang selain mereka yang tidak seperti itu. Karena sesungguhnya seseorang yang menggunakan akalnya dengan baik, seperti untuk belajar, maka pengetahuan mereka akan bertambah dan keimanan mereka juga meningkat. ${ }^{23}$

c. Surat At-Taubah ayat 122. (Akal untuk mempelajari ilmu pengetahuan demi keberlangsungan pendidikan umat)

Allah SWT berfirman, "Tidak seharusnya semua orang beriman pergi ke medan perang. Kenapa tidak setiap dari kaum mereka mewakili orang untuk memperdalam pengetahuan agama dan untuk memperingatkan kaumnya ketika mereka telah kembali, supaya mereka dapat menjaga diri" (Q.S. At-Taubah: 122). Ayat ini turun ketika para sahabat seluruhnya sedang bersemangat setiap ada panggilan jihad ke medang perang, sampai mereka lupa dengan keadaan keluarganya yang sedang sakit atau memiliki kebutuhan lainnya. ${ }^{24}$ Melihat ayat di atas secara tidak langsung merupakan perintah kepada semua orang beriman untuk tidak hanya fokus dengan jihad fi sabilillah di medang perang, melainkan juga fokus terhadap pendidikan (ijtihad/akal) umat demi menyiapkan generasi selanjutnya dengan mempelajari ilmu pengetahuan. Karena dikhawatirkan bila banyak dari sahabat yang berjihad di medang perang telah menemukan syahidnya sedangkan ilmu belum tersebar begitu luas. Oleh karena itu perlu ada keseimbangan dalam membagi amal-amal shaleh tersebut.

d. Surat Ali-Imran ayat 190-191 dan Surat Al-Baqarah ayat 164. (Akal untuk berdzikir, mengingat dan mengagungkan Allah)

Kedua ayat ini memiliki isi kandungan yang serupa, yaitu Allah SWT menegaskan bahwa akal merupakan pemberian dari Allah yang seharusnya digunakan kembali untuk mengingat dan memuji-Nya. Banyak manusia menjadi sombong dan angkuh sebab mereka lupa siapa penciptanya dan tidak menggunakan akalnya untuk memikirkan tentang penciptaan alam semesta. Ayat

22 Imam As-Suyuthi, Asbabun Nuzul, terj. Muhammad Miftahul Huda, (Sukoharjo: Insan Kamil, 2016), hlm. 604.

${ }^{23}$ Muhammad Fatoni dan Ahmad Fikri Amrullah, "Penafsiran Kontekstual Ayat-Ayat Tarbawi” jurnal Ilmu-Imu Ushuluddin vol. 07, no. 01, Juli 2019, hlm. 22.

${ }^{24}$ Abil Hasan Ali, Asbabun Nuzul, (Lebanon: Darul Kutub al-ilmiyah, 2011), hlm. 138. 
ini dengan jelas memerintahkan bagi orang-orang yang berakal serta beriman untuk memikirkan pergantian siang dan malam, tenggelamnya matahari dan munculnya bulan. Dengan pergantian itu manusia dapat merasakan nikmat yang begitu besar, karena dalam menjalani hidup manusia dapat merasakan panasnya matahari dan dinginnya bulan (malam). Sehingga akhir dari pemikiran ini adalah bahwa semua ciptaan Allah memiliki manfaat bagi kemaslahatan dan kehidupan di muka bumi dan tidak sia-sia, semuanya secara teratur memberikan fungsinya demi menjaga kelangsungan tatanan langit dan bumi. ${ }^{25}$ Implementasinya dalam pendidikan Islam menjadikan manusia yang beriman tidak angkuh ketika diberikan akal dan ilmu pengetahuan karena dengan memikirkan penciptaanNya yang lebih besar (langit dan bumi) mereka menyadari bahwa akal mereka terbatas, sehingga harus patuh kepada penciptanya, Allah SWT'

e. Surat Al-Ghasiyah ayat 17-20 (Akal untuk memperhatikan dan berpikir dengan detail)

Allah SWT berfirman, "Apakah mereka tidak memperhatikan bagaimana unta itu diciptakan? Dan langit ditinggikan? Dan gunung-gunung ditegakkan? Dan bumi dihamparkan?” (Q.S. Al-Ghasiyah: 17-20). Dalam ayat ini Allah memaparkan dengan lebih detail tentang semua penciptaannya agar manusia dapat lebih membuka mata dan menggunakan akalnya untuk memikirkan kebesaran Allah SWT. Ayat ini turun di Arab yang mayoritas penduduknya memiliki unta sebagai hewan kebanggaannya. Oleh karenanya ayat ini memerintahkan mereka untuk memikirkan bagaimana proses penciptaan unta dan seberapa besar manfaatnya untuk mereka gunakan di padang pasir. Lalu ketika mereka melihat ke atas seketika ia melihat langit yang dapat berdiri kokoh tanpa tiang penyangga. Lalu mereka melihat daerah sekitar tempat mereka tinggal dikelilingi oleh gunung-gunung yang berdiri tegak. Lalu mereka memandang lurus ke depan terhampar jelas bumi yang luas tempat mereka tinggal. Maka Allah memerintahkan mereka untuk merenungkan dan berpikir secara mendalam tentang itu semua. ${ }^{26}$ Implementasi ayat ini dalam pendidikan Islam bahwa manusia diperintahkan menggunakan akalnya untuk berpikir kritis dan mendalam. Ayat tersebut hanya membicarakan tentang unta, langit, gunung, dan bumi, namun sesungguhnya Allah memerintahkan manusia untuk berpikir dengan lebih luas lagi yaitu segala hal yang dapat terlihat, terdengar, dan terbesit dalam hati. Karena semakin mendalam pemikiran manusia, mereka akan semakin cerdas, semakin bijak, berhati-hati dalam berbuat, yang itu semua dapat

${ }^{25}$ Kurnia Indriyani, "Konsep Ulul Albab Dalam Pendidikan Islam (Analisa Surat AliImran Ayat 190-191)", Skripsi, Pendidikan Agama Islam, Fakultas Tarbiyah dan Ilmu Keguruan, Institut Agama Islam Negeri Salatiga, 2017, hlm. 17-18.

${ }^{26}$ Ahmad Mustafa Al-Maragi, Terjemahan Tafsir Al-Maragi (Semarang: PT Karya Toha Putra, 2010), hlm. 195. 
menghindarkan mereka dari ucapan atau perbuatan yang tidak diinginkan dalam pendidikan Islam. $^{27}$

\section{Kesimpulan}

Akal merupakan anugerah terbesar dari Allah yang diberikan kepada manusia. Namun banyak manusia yang menyalahgunakan pemberian Allah tersebut. Tidak sedikit dari manusia yang menggunakan akalnya hanya untuk menuruti hawa nafsu belaka. Oleh karena itu tulisan ini berusaha untuk menemukan konsep akal dalam Al-Quran dan bagaimana relevansi dengan dunia pendidikan Islam menggunakan tafsir Maudhu'i. Dalam perspektif Islam, akal dan ilmu merupakan dua hal yang terkait dan tak terpisahkan, karena salah satu fungsi utama akal bagi manusia adalah untuk menerima segala jenis informasi/pengetahuan. Adapun di dalam Al-Quran ternyata banyak sekali menyimpan tuntunan bagaimana seseorang yang beriman menggunakan akalnya dengan baik dan benar, yaitu untuk berpikir, menerima segala jenis pengetahuan, merenung, membedakan antara haq dan batil, benar dan salah, taqwa dan nafsu, serta untuk berdzikir, mengingat, dan meningkatkan iman seorang hamba kepada Allah SWT.

\section{Bibliografi}

Anis. Muh. 2012. Tafsir Ayat-Ayat Pendidikan Meretas Konsep Pendidikan dalam Al-Quran. Yogyakarta: mentari pustaka.

As-Suyuthi, Imam. 2016. Asbabun Nuzul, terj. Muhammad Miftahul Huda, Sukoharjo: Insan Kamil.

Chairuni, Khudiatul. 2019. "Pengaruh Keaktifan Belajar PAI Terhadap Religiusitas Peserta Didik Di SMP Bakti Mulya 400 Jakarta”, Skripsi, Pendidikan Agama Islam Fakultas Ilmu Tarbiyah Dan Keguruan Universitas Islam Negeri Syarif Hidayatullah Jakarta.

Cyril Glasse. 1996. Ensiklopedi Islam Ringkas Terjemah Ghufron Masadi, Jakarta: RajaGrafindo Persada.

Farid, Achmad. 2018. Jejak Sejarah Andalusia, cet.1. Yogyakarta: Checklist.

27 Melindayani Pulungan, "Nilai-Nilai Pendidikan Islam dalam Al-Quran Surat AlGhasiyah Ayat 17-22”, Skripsi, Program Studi Pendidikan Agama Islam, Fakultas Tarbiyah dan Ilmu Keguruan, Institut Agama Islam Negeri Padang Sidimpuan, 2017, hlm. 67. 
Fatoni, Muhammad, dan Ahmad Fikri Amrullah. 2019. "Penafsiran Kontekstual Ayat-Ayat Tarbawi (Pendekatan Asbabun Nuzul)", jurnal Ilmu-Ilmu Ushuluddin vol. 07, no. 01.

Hamid Wahid, Abd, Chusnul Muali dan Arofah Aprilia Putri. 2018. "Rekonstruksi Pendidikan Islam Kontemporer Dalam Perspektif Transformasi Sosial", jurnal Pendidikan Islam, Vol.07, No. 01.

Hasan Ali, Abil. 2011. Asbabun Nuzul. Lebanon: Darul Kutub al-ilmiyah.

Indriyani, Kurnia. 2017. "Konsep Ulul Albab Dalam Pendidikan Islam (Analisis Surat Ali-Imran Ayat 190-191)", Skripsi, Jurusan Pendidikan Agama Islam, Fakultas Tarbiyah dan Ilmu Keguruan, Institut Agama Islam Negeri (IAIN) Salatiga.

Mahfudz, Muhammad. 2006. Peran Akal Dalam Surat Ali Imran Ayat 190-191 Dan Implikasinya Dalam Pendidikan Islam. Semarang: Fakultas Tarbiyah IAIN Walisongo.

Munawwir. 1997. Kamus Al-Munawwir Arab-Indonesia, Surabaya: Pustaka Progressif.

Mustafa Al-Maragi, Ahmad. 2010. Terjemahan Tafsir Al-Maragi. Semarang: PT Karya Toha Putra.

Musyafa, Haldar. 2015. Dahsyatnya Potensi Akal Dan Hati Kita. Yogyakarta: Suka Press.

Nashih 'Ulwan, Abdullah. 2012. Pendidikan Anak dalam Islam. Terj. Arif Rahman Hakim dan Abdul Halim). Solo: Insan Kamil.

Poerwadarminta. 2007. Kamus Umum Bahasa Indonesia, Jakarta: Balai Pustaka.

Pulungan, Melindayani. 2017. "Nilai-Nilai Pendidikan Islam Yang Terkandung dalam Al-Quran Surat Al-Ghasiyah Ayat 17-22”, Skripsi, Program Studi Pendidikan Agama Islam, Fakultas Tarbiyah dan Ilmu Keguruan, Institut Agama Islam Negeri Padang Sidimpuan.

Sururin. 2004. Ilmu Jiwa Agama. Cet. ke-1. Jakarta: PT. Raja Grafindo Persada.

Tim Penyusun. 2005. Ensiklopedi Islam, Jild. 1, Jakarta: Ichtiar Baru Van Hoeve.

Tim Redaksi. 2005. Kamus Besar Bahasa Indonesia Edisi III, Jakarta: Balai Pustaka.

Wasehudin, 2018. 'Akal Dalam Perspektif Pendidikan Islam', Jurnal Al Qalam, Vol. 35, No. 2. 